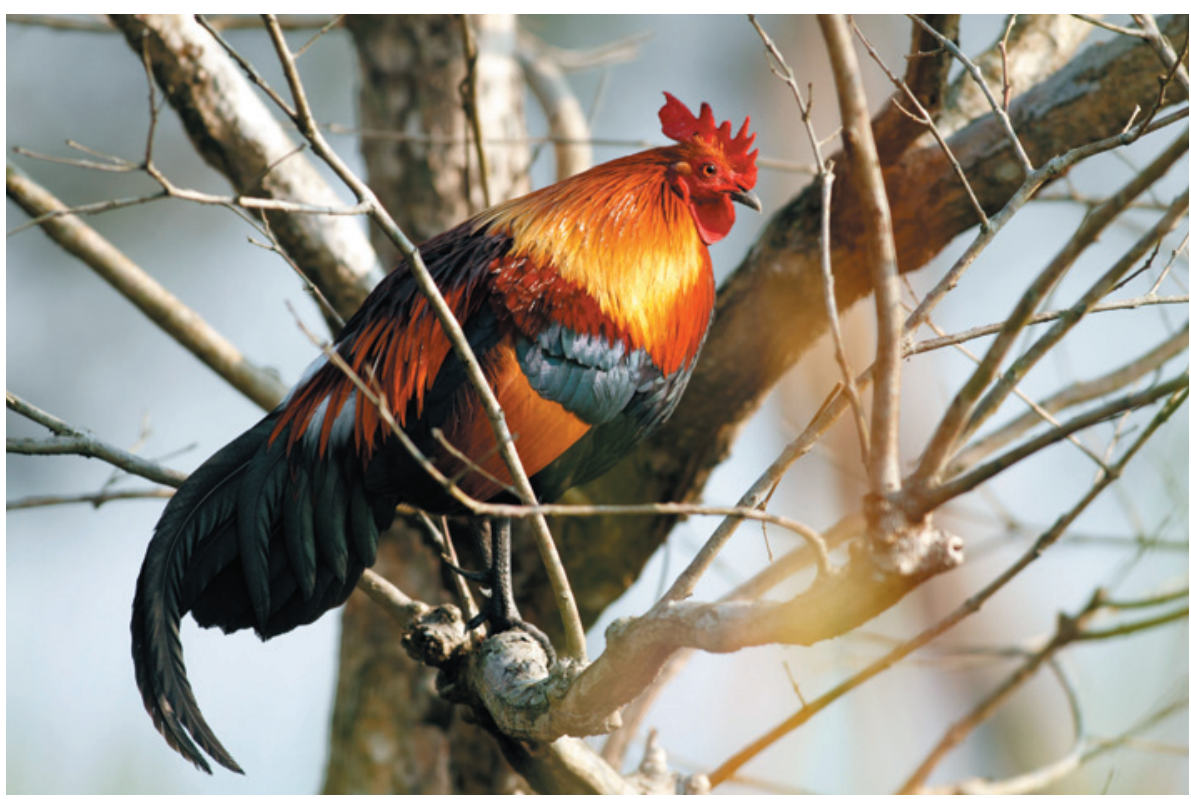

Modern chickens are descended primarily from the red junglefowl.

EVOLUTION

\title{
Chicken project gets off the ground
}

\section{Effort aims to unravel the history of bird's domestication.}

\section{BY EWEN CALLAWAY}

$\mathrm{T}$ The meat and eggs of domestic chickens are a source of protein for billions. Yet how and when the birds were domesticated remains a mystery. The answers to these questions could reveal a wealth of information about the genetics of domestication, as well as human behaviour, and how we can improve our husbandry of the birds.

In a bid to learn more about the chicken and its lineage, the UK government is funding a $£ 1.94$-million (US\$3.3-million) effort to determine how the chicken went from being a wild fowl roaming the jungles of southeast Asia several thousand years ago to one of the world's most abundant domesticated animals. The Cultural and Scientific Perceptions of HumanChicken Interactions project - 'Chicken Coop' for short - will examine human history from the perspective of the fowl.

"No one ever considers chickens, which is a massive mistake," says Holly Miller, an archaeologist at the University of Nottingham, UK. She was one of two dozen researchers, from anthropologists to geneticists, who attended the second meeting of the five-month-old project at the University of Roehampton, UK, last week.

Another was Greger Larson, an evolutionary geneticist at Durham University, UK, who is a senior scientist on the project. He says that researchers studying domestication tend to overlook chickens in favour of other domesticated animals, such as dogs, cows and pigs.

But no domestic animal has been moulded and remoulded by humans as extensively as chickens, says Larson. The animals have been bred for eating, egg-laying and fighting. And in the case of one particularly vocal breed, the creatures have even been strapped to the masts of Polynesian boats to act as foghorns. "Chickens are polymaths," he says.

Larson, who studies DNA from the remains of ancient chickens, discovered last year that modern chickens can be deceptive. Previous studies have compared the DNA of modern chicken breeds with that of species of junglefowl that contributed to the gene pool of early chickens, such as the red junglefowl ${ }^{1,2}$. The work identified variants in two genes that are common in contemporary chickens but not in junglefowl.

One variant - when present in two copies — gives domestic chickens their familiar yellow skin and legs when they consume a diet rich in carotenoids; this trait is almost universal in European chickens. The other is a variant of the thyroid-stimulating hormone receptor gene (TSHR) that may alter the seasonal mating patterns of chickens and allow them to lay eggs all year round. It is universal in modern breeds $\Sigma$ such as Rhode Island Reds and broiler chickens.

Because these mutations are so common in contemporary chickens, Larson's team and others assumed that humans influenced these traits through selective breeding early in the course of domestication. But DNA from chickens recovered at archaeological sites across Europe, spanning the period from around $280 \mathrm{BC}$ to $\mathrm{AD} 1800$, has turned that idea on its head. In an analysis published last month, Larson's team reported that none of 25 ancient chickens would have had yellow legs, and that just 8 out of 44 birds carried two copies of the TSHR variant ${ }^{3}$. So even 200 years ago, chickens may have been very different from those we know today.

With the help of other Chicken Coop members, Larson is also trying to get to grips with the wider evolutionary forces that shaped modern chickens. He hopes to determine why, for instance, chickens have not been wiped out by disease. This might have been expected because their very rapid selection ${ }^{2}-$ much of which has taken place since 1900 - should have led to inbreeding and, by whittling down immune genes, a reduced ability to respond to infections.

Other members of Chicken Coop are tackling different aspects of the bird's past. Miller plans to analyse the diet of ancient chickens, using chemical isotopes in their bones and egg shells, to reveal information on the resources available to the humans who kept them. Another team, at the University of Leicester, UK, will compare chicken bones from archaeological sites with bones of modern breeds. Known pathologies in today's birds can then be used to determine how diseases and breeding changed through time.

John Hutchinson, an evolutionary biomechanist at the Royal Veterinary College in London, thinks that a better understanding of the bird's history will help people to address some of the problems facing chickens and the poultry industry, such as avian influenza and leg weakness among broiler chickens. Research on ancient breeds could help us to "refresh the genetics" of broilers, he suggests. Last month, Hutchinson ran a conference, Towards the Chicken of the Future, to tackle such issues. "Science has got us into this problem through intense selection," he says. "It can maybe help us out of it." -

1. Eriksson, J. et al. PLoS Genet. 4, e1000010 (2008).

2. Rubin, C.-J. et al. Nature 464, 587-591 (2010).

3. Flink, L. G. et al. Proc. Natl Acad. Sci. USA http:// dx.doi.org/10.1073/pnas.1308939110 (2014).

\section{CORRECTION}

The News story 'Text-mining offers clues to success' (Nature 509, 410; 2014) wrongly implied that SRI International is based in Arlington, Virginia. Although it has an office there, it is based in Menlo Park, California. It also should have said that IARPA is funding, not partnering with, SciCast, a project run by George Mason University and the American Association for the Advancement of Science. 